Bei mehreren auf diese Art angestellten Analysen stellte sich heraus, dass die Gegenwart dieser Extractivstoffe auf diese Art der Harnstoffbestimmung ohne wesentlichen Einfluss ist.

Eine unvermeidliche, aber den angestellten Versuchen gemäss doch unerhebliche Fehlerquelle, hat ihren Grund in der nicht vollständigen Unlöslichkeit des kohlensauren Baryts in reinem oder salmiakhaltigem Wasser. Eine zweite Fehlerquelle liegt in dem geringen Kreatingehalte des Harns, welcher Sioff mit ammoniakalischer Chlorbaryumlösung bis uber $220^{\circ}$ erhitzt in Sarkosinsalmiak und kohlensauren Baryt zerfällt. Da jedoch der Kreatingehalt im Harn so sehr geringfügig ist, so wirkt der dadurch bedingte Fehler dem durch die Löslichkeit des kohlensauren Baryts hervorgerufenen entgegen.

Da nach dieser Methode ohne grosse analytische Gewandtheit binnen kurzer Zeit eine Menge solcher Harn. stoffbestimmungen von einer Person ausgefuhrt werden konnen, so ist dieselbe unter den bisher vorgeschlagenen, als ein, wenn auch nicht allen Ansprüchen genügende, doch mit einer hinlänglichen Genauigkeit, die allgemeinste Anwendbarkeit verbindende, zu betrachten. (Annalen der Chem. u. Pharm. Bd.61.p. 375.) E. St.

\title{
Saure und alkalische Reactionen der thierischen Flüssigkeiten.
}

Andral hat über die Meinung, dass in Krankheiten die sauren Flissigkeiten eine alkalische Reaction, die alkalischen eine saure annehmen könten, neue Versuche angestellt.

Das Blutserum zeigt unter allen thierischen Fluissigkeiten die stärkste alkalische Reaction, und die Krankheiten wirken nicht verändernd ein. Der Bcobachtung, dass zu Zeiten, wo eine Verminderung des Fiebers im Blute eingetreten ist, eine Zunahme der alkalischen Bestandtheile eintrete, legt Andral kein Gewicht bei, auch der Angabe nicht, dass bei Diabetes mellitus die Alkalität des Blutes geringer sei.

Gegen die Ansicht von Scheerer hält Andral diə alkalische Reaction dem Blute allgemein zukonmend. Bei Beurtheilung der Fliissigkeiten, die sich auf Kosten des Blutes bilden, (sie sind selten neutral) darf man sich nicht täuschen lassen, da leicht der grösste Theil innerer und äusserer Oberflächen von alkalischen oder sauren Flüssigkeiten bedeckt sein, und somit einen scheinbaren Wechsel 
der Reaction veranlassen kann. Der Schweiss reagirt sowohl im kranken als auch gesundem Körper immer sauer, nur bei starker Absonderung, z. B. wenn viel Wasser in den Magen gelangt, tritt zuweilen ein neutraler $\mathrm{Zu}-$ stand ein.

Die Fettmaterie der Haut hat eine alkalische Reaction, ilso findet man an gewissen Orten der Haut, namentlich wo sich viel Fettbälge anhäufen, selbst bei Vorhandensein von Schweiss eine alkalische Reaction.

Den Schweiss kann man nicht als ein mil den Bestandtheilen des Blutserums beladenes Wasser betrachten, sonst müsste er wie das Serum und diejenigen Flüssigkeiten, welche sich an der Oberfläche der Haut aus dem Blute abscheiden, alkalisch sein. Ueberall wo ein mehr oder weniger intensiver Congestionsprocess der Aussonderung der Flüssigkeit vorangeht, kann man immer annehmen, dass das Blutserum verändert aus den Gefässen tritt und sich frei an die Hautoberfläche begiebt; z. B. bei Verbrennung, beim Legen eines Spanisch-Fliegenpflasters etc. sammelt sich stets an der Hautoberflache eine alkalische Fliissigkeit. Bei Herpes oder Eczema etc. findet sich in den Blasen ebenfalls ein alkalisches Fluidum. Die Flüssigkeiten der Sudamina (blasiger Haulausbruch) sind übrigens sauer; es geht diesen keine Congestion voraus, und jene Flüssigkeiten gleichen wegen Abwesenheit des Eiweisses und der sauren Reaction dem Schweisse.

Auf gesunden Schleimhäuten findet man immer eine saure Substanz, welche in der klaren, von Kügelchen freien Flussigkeit existirf, und ein Secret des Blutes ist. Kömmt aber die zweite opake mit Kiigelchen versehene [lüssigkeit hinza, so tritt cine alkalische Reaction ein.

Der Mucus puriformis der Nasenhöhlen ist bei Coryza sehr stark alkalisch. Dor Auswurf bei Bronchitis ist of sauer und alkalisch zugleich; der trübe ist alkalisch, der klare sauer.

Im niichternen Zustande ist die Schleimhaut des Mundes meist sauer, wird aber im Laufe des Tages alkalisch. Erstere Reaction rührt von der von der Membrana mucosa buccal. abgesonderten Materie, letzlcre vom Speichel her. Also hat die Säure im Munde keine pathologische Bedingung.

Der Verfasser konnte nicht finden. dass die Magenschleimhaut eine saure Reaclion zeigte bei durch Nabrung gereiztem Magen, und bei leerem Magen eine alkalische. Nach dem Tode war sie meist saver, sehr selten alkalisch. Den sauren Zustand fand Andral bei Fiebern, acuten Entzuindungen der Lungen, Phthisis derselben, Albuminosis 
und Diabet. mellitus. In den durch Erbrechen entleerten Materien ist die Reaction fast constant sauer.

Die Schleimhäute des Duodenums und des Dünndarms zeigen nach dem Tode beim Menschen auf der Oberfläche oft saure Fliissigkeiten, welche durch die Ergisse des Pancreas und der Galle häufig neutralisirt oder alkalisch erscheinen. Die Flüssigkeit des Dickdarms war immer alkalisch. Was oben schon von dem 'Speichel erwähnt ist, dass derselbe alkalisch reagire, gilt auch von den Thränen.

Der normale Schleim ist stets sauer, kann aber bei grossen Mengen von Getränken seine Reaction verlieren, wenn sie nicht durch eine gleichzeitige starke Schweissabsonderung wieder eintritt. Andral hat bei seinen Versuchen gefunden, dass, so lange die Harnblase gesund ist, der sauren Reaction des Harns kein Abbruch geschieht. Nur durch manche Nahrungsmittel kann der Harn alkalisch werden, bei Enthaltung der Nahrung aber nicht. Merkwürdiger Weise tritt aber öfters eine vorübergehende alkalische Reaction ein, wenn Reconvalescenten wieder Nahrung za sich nehmen. Bei Bildung von Eiter in der Harnblase ist der Harn alkalisch, was also von einer veränderten Nierenthätigkeit nicht abgeleitet werden kann. Uebrigens zeigt sich der Eiter selbst alkalisch, ohne eine Zersetzung durch den Harn erlitten zu haben; nur wenn der Luft-zutritt weiter verändernd einwirkt, tritl eine saure Reaction ein. (Compt rend. Tome XXVl. - Pharm. Centrbl. 1848. No. 41.)

B.

\section{Fabrikation der reinen Schwefelsäure.}

Aug. A. Hayes sucht die organische Substanz durch einen hinreichenden Zusatz von Kali - oder Natronsalpeter zu zerstören, wodurch die Schwefelsäure farblos wird. Ist Salzsäure vorhanden, so wird diese grösstentheils durch die Salpetersïure zerselzt, ist es schweflige und arsenige Säure, so werden diese büher oxydirt. Man concentrirt dio Säure nun bis zu 1,78 sp. G. und setzt dann eine passende Menge Bleioxyd hinzu. Durch Absetzen, Abgiessen und starkes Ablü̈hlen bis zur Krystallisation der Hälfte des Fluidums erhält man nach dem Auswaschen der Krystalle mit reiner Säure und Schmelzen derselben, in vorher mit gewöhnlicher Schwefelsäure ausgewaschenen Bleikesseln, eine fast reine Säure, welche in Platinkesseln weiter concentrirt werden kann. Will man eine sehr reine Säure haben, so muss man die Krystalle in Glasgefässen schmelzen und wiederum bis zur Hälfte auskrystallisiren lassen. (Sillim. americ. Journ. Vol, 17. - Pharm. Centrbl. 1848. No. 49.) 